\title{
Vitellogenesis in the giant tiger prawn, Penaeus monodon Fabricius, 1789
}

\section{Che-Chun Chen* and Shiu-Nan Chen $\dagger$}

Department of Aquaculture, National Chiayi Institute of Agriculture, Chiayi, Taiwan 60083, Republic of China; and †Department of Zoology, National Taiwan University, Taipei, Taiwan 106, Republic of China

Vitellogenesis can be induced in the ovaries of the penaeid shrimp, Penaeus monodon, by eyestalk ablation; $80 \%$ of shrimp spawned within 7 days after ablation. Using immunofluorescence, it was observed that vitellin commences to accumulate in the yolk globular stage oocytes. The vitellin of atretic oocytes is reabsorbed and transferred to the newly matured oocytes. Four vitellin-like peptides are synthesized in vitro by the ovaries with mol. wt 220, 168, 130 and $74 \mathrm{kDa}$, respectively. Amongst them, the 168 and $74 \mathrm{kDa}$ peptides are secreted into the culture medium. The results of immurostaining showed that the anti-Ep antisera is able to react with the ovary extracts of Penaeus japonicus. Each antiserum may react to the compatible peptide of the $P$. monodon vitellin peptide.

Key words: Penaeus monodon Fabricius; Vitellogenesis.

Comp. Biochem. Physiol. 107B, 453-460, 1994.

\section{Introduction}

Vitellin ( $\mathrm{Vt})$, a major egg yolk protein, is synthesized on a large scale in the yolk production tissues which, in vertebrates are the liver and ovary and, in insects, the fat body and ovary. The primary translation products are precursor molecules, vitellogenins $(\mathrm{Vg})$, which may be cleaved and modified to yield the mature yolk proteins in the course of secretion, transport and deposition in the developing oocyte. In several species of crustaceans, vitellogenin has been isolated and characterized; it has been described as a lipoglycol-carotenopoprotein (Tom et al., 1987; Quinitio et al., 1990; VazquezBoucard and Ceccaldi, 1986; Yano and Chinzei, 1987; Rankin et al., 1989; Browdy et al., 1990). In several species of decapod crustaceans, the ovary (OV) (Quackenbush, 1989; Yano and Chinzei, 1987; Browdy et al., 1990; Rankin et al., 1989), subepidermal adipose tissue (SAT) (Aiken and Waddy, 1980; Tom et al., 1987) and hepatopancreas (HP) (Vogt et al., 1989; Paulus and Laufer, 1987) have been implicated in con-

Correspondence to: Che-Chun Chen, $\mathrm{Rm}$ 203, The Institute of Fishery Biology, National Taiwan University, Taipei, Taiwan 106, Republic of China.

Received 16 June 1993; accepted 30 July 1993. tributing to synthesis of vitellin or its precursor molecule, vitellogenin.

Ovarian development in crustaceans may be promoted by eyestalk ablation in several species of penaeid shrimps. In Penaeus monodon, the isolated vitellin possesses a molecular weight of approximately $540 \mathrm{kDa}$ and is composed of four major subunits of mol. wt 74, 83, 104 and $168 \mathrm{kDa}$ (Quinitio et al., 1990). Egg extracts are immunologically identical to hemolymph of maturation stage female shrimp (Chen and Chen, 1993). Previously, we have studied the synthesis of vitellin in ovarian culture in vitro. The present study showed that a non-secreted vitellogenin precursor (pre- $\mathrm{Vg}$ ) is proteolytically cleaved within the ovary into two products with molecular weights of over $200 \mathrm{kDa}$ and secreted into the culture medium.

\section{Materials and Methods}

Animals

Broodstock female $P$. monodon were obtained from Tungang, southern Taiwan. Shrimp were maintained in seawater $2.8 \%$ at $28 \pm 1{ }^{\circ} \mathrm{C}$ and fed squid and oysters twice daily. Unilateral eyestalk ablation induces ovarian development. 
Table 1. The number of nauplius produced from 25 Penaeus monodon females

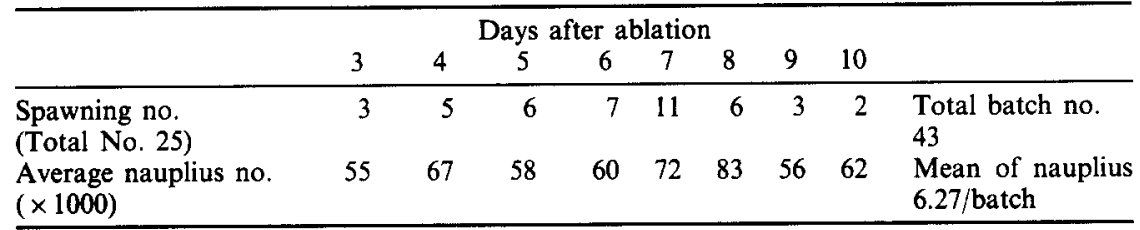
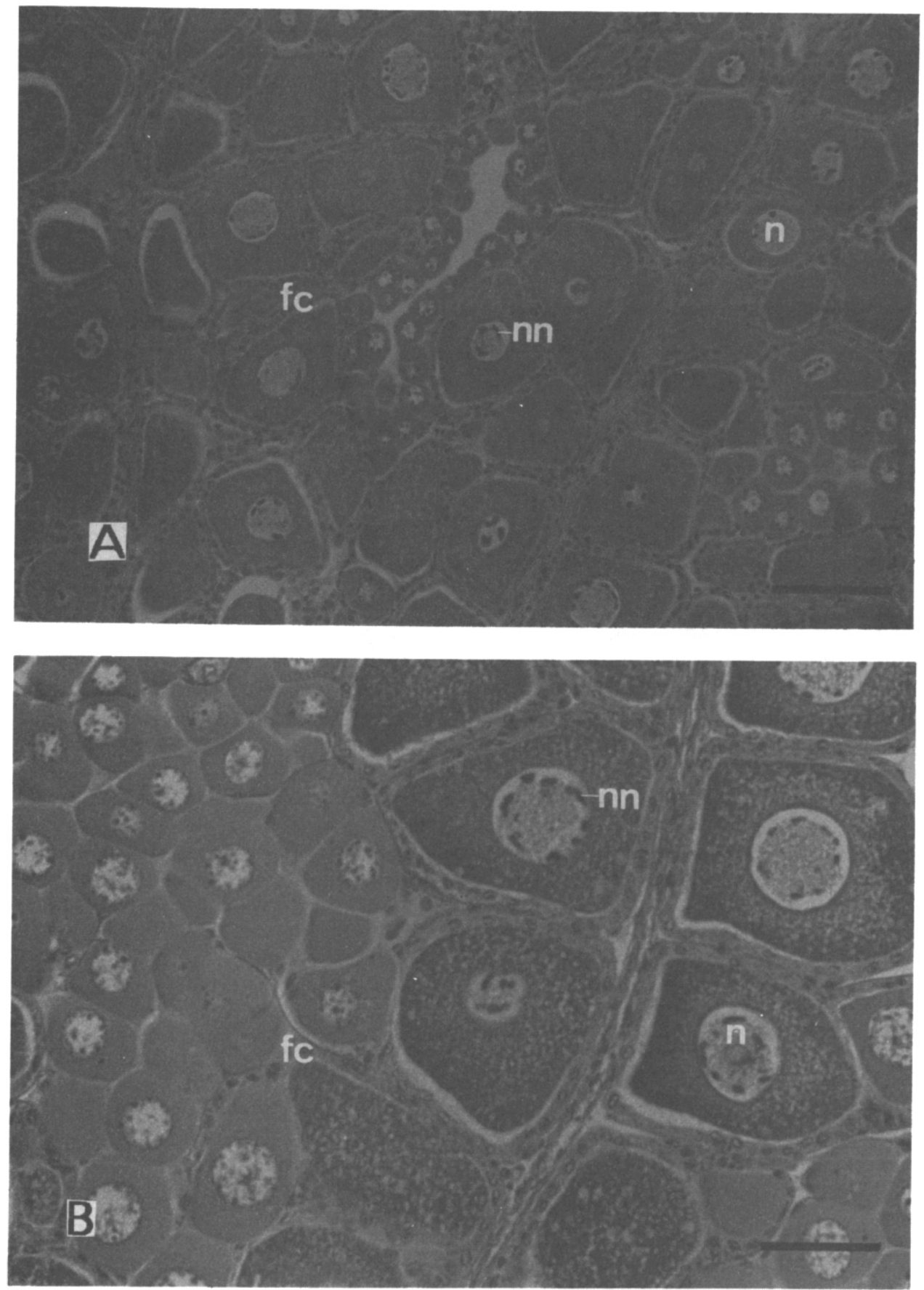

Fig. 1. Histologic section of ovaries of Penaeus monodon which were taken for in vitro culture ( 3 days after eyestalk ablation). A, HE stain; B, PAS stain; n, nucleus; nn, nucleoli; fc, follicle cell. Scale: $100 \mu \mathrm{m}$ (A), $50 \mu \mathrm{m}$ (B). 
The vitellogenesis stage was confirmed visually using the criteria described by Motoh (1981).

In vitro organ culture

Tissues dissected from early vitellogenic females were incubated in $200 \mu 1(2 \times)$ Leibovitz's L-15 medium (Hazleton), with osmolarity of $720 \pm 10 \mathrm{mmol} / \mathrm{kg}$ at $28 \pm 1^{\circ} \mathrm{C}$ as described by Chen et al. (1989). New synthetic vitellogenins were labeled in methionine-free medium with $200 \mu \mathrm{Ci} / \mathrm{ml}{ }^{35} \mathrm{~S}-m e t h i o n i n e$ (specific activity $1209.3 \mathrm{Ci} / \mathrm{mmol}$ ). After incubation, tissue and medium were centrifuged at $15,000 \mathrm{~g}$ for $10 \mathrm{~min}$ in an Eppendorf microfuge at $4^{\circ} \mathrm{C}$.

\section{Immunoprecipitation with anti-Ep-serum}

Crude tissue extracts $(100 \mu l)$ or culture medium $(100 \mu \mathrm{l})$ were added to $50 \mu 1$ anti-Ep- serum and $50 \mu 1$ protein-A Sepharose CL-6B with incubation at $4^{\circ} \mathrm{C}$ for $4 \mathrm{hr}$ or overnight. The precipitated pellet, after washing twice with $0.1 \mathrm{M}$ Tris- $\mathrm{HCl}$ buffer ( $\mathrm{pH} 7.5$ ), was redissolved in $50 \mu 1$ SDS sample buffer.

\section{Indirect immunofluorescence microscopy}

Paraffin sections were prepared according to standard methods. Tissue sections were incubated with $200 \times$ anti-Ep-serum for $1 \mathrm{hr}$ at room temperature, and washed with TBS. FITC-conjugated goat IgG (anti-rabbit-IgG, 1:20 diluted) was applied for $1 \mathrm{hr}$ at room temperature. The sections were mounted in $1 \mathrm{M}$ Tris- $\mathrm{HCl}(\mathrm{pH} 8.1)$ and glycerol $(1: 9, \mathrm{vol} / \mathrm{vol})$ then observed and photographed with an Olympus (Model BH2) microscope, with an incident UV attachment and fluorescence optics.

A
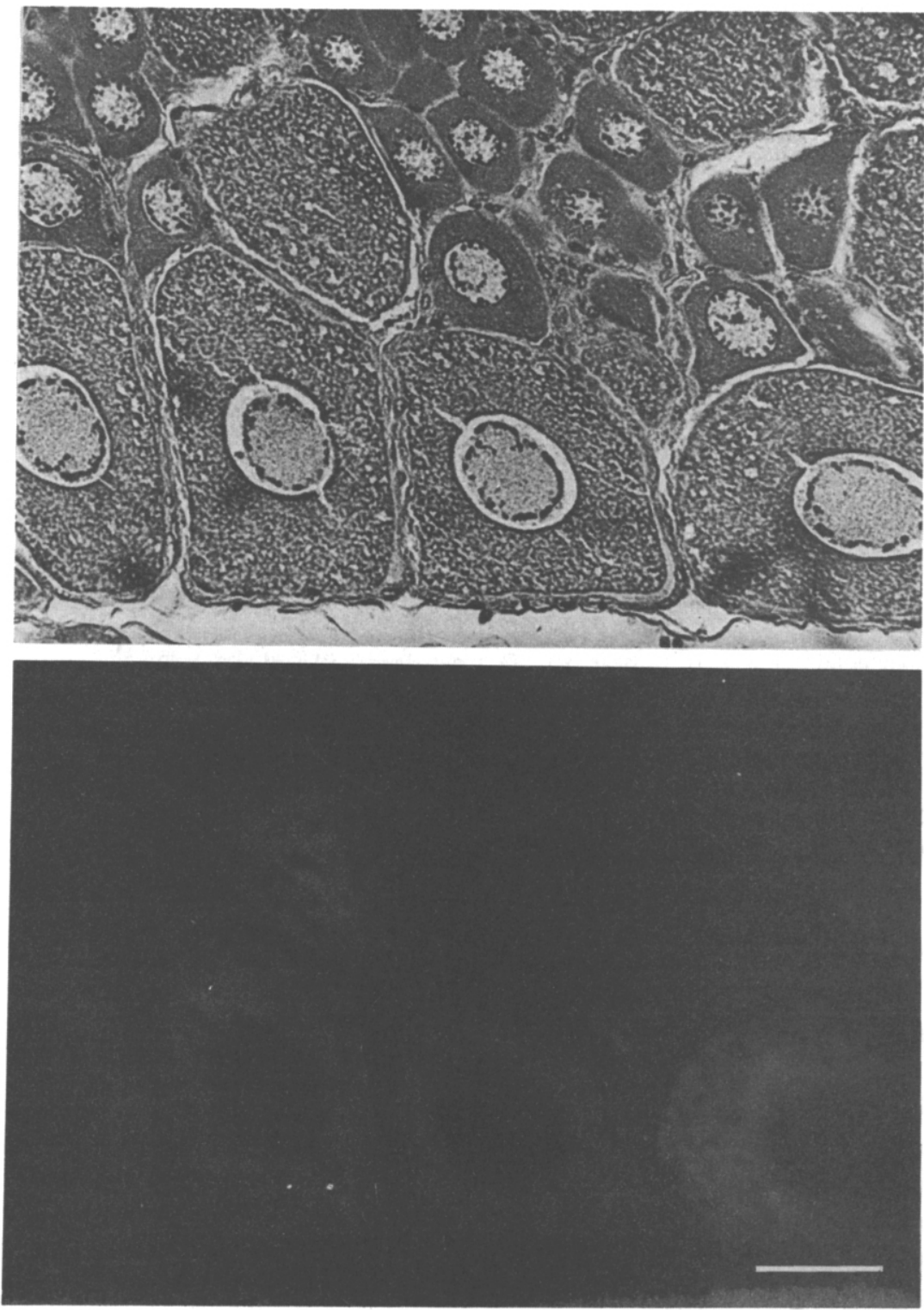

Fig. 2A and B 


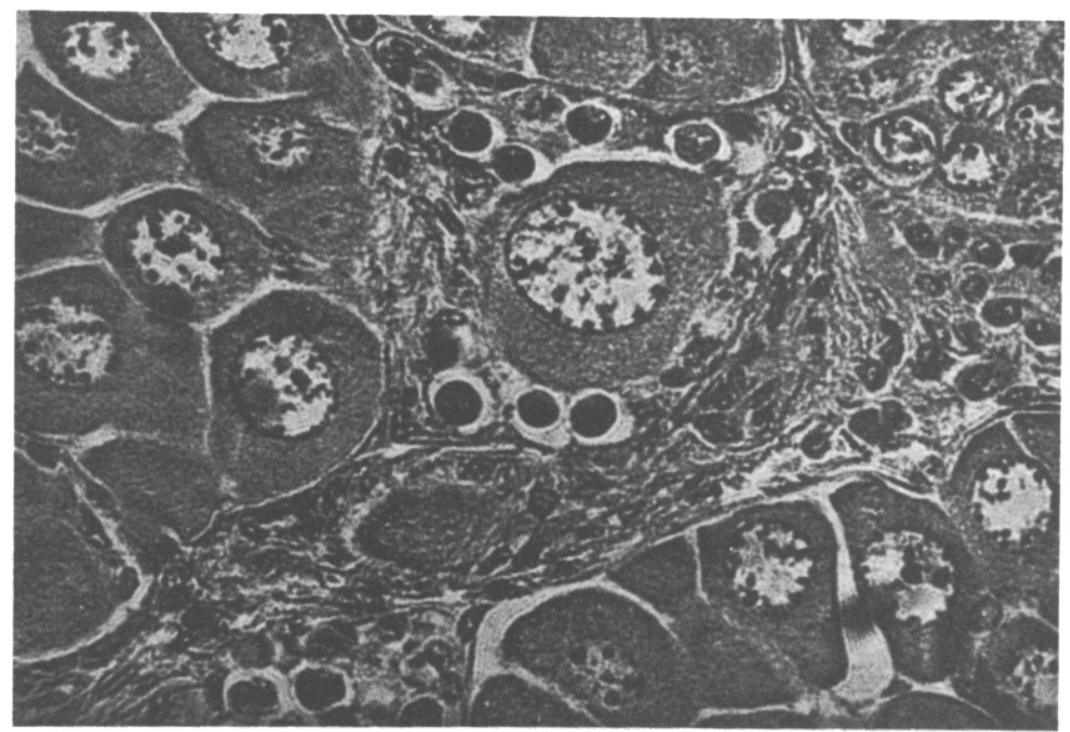

D

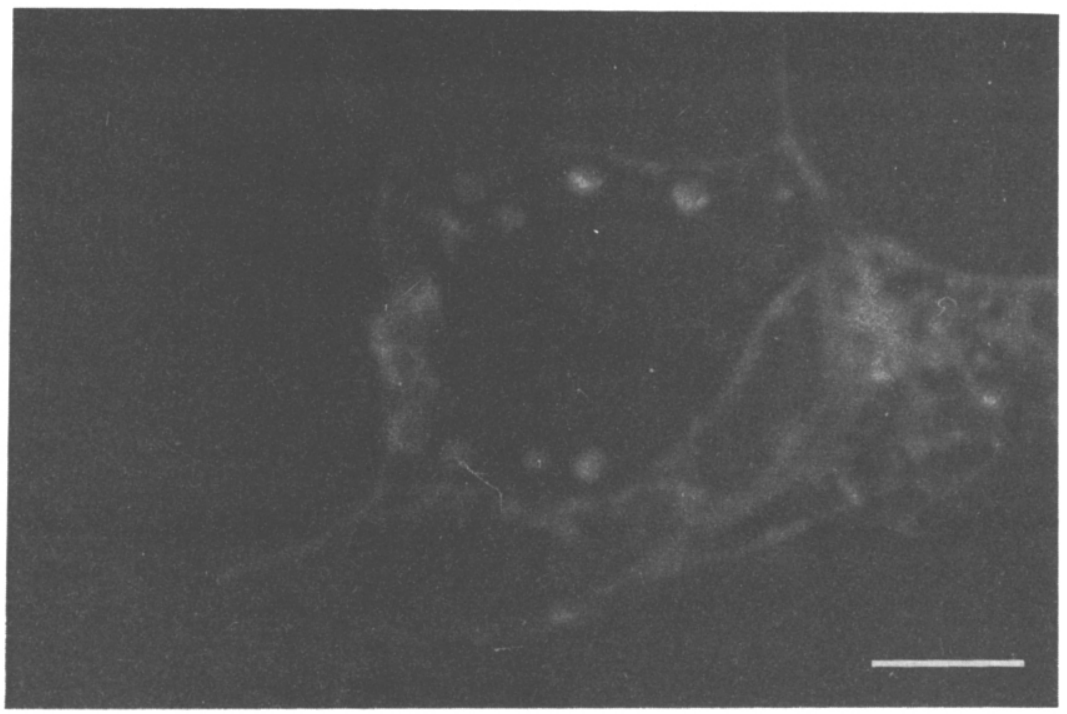

Fig. 2. Immunofluorescence microscopy of developing ovaries of $P$. monodon. A, C, phase contrast; B, D, immunofluorescence. A, B, stage 1; C, D, spent stage. Scale: $50 \mu \mathrm{m}$ (A, B); $100 \mu \mathrm{m}$ (C, D).

Digestion of $\mathrm{Vg}$ with Endo-H and calf alkaline phosphatase

The culture medium was incubated in $20 \mathrm{mM}$ Tris- $\mathrm{HCl}$ buffer plus 20 units of calf alkaline phosphatase (EC 3.1.3.1) (pH 8.0), at $37^{\circ} \mathrm{C}$ for $2 \mathrm{hr}$. The reaction was stopped by adding SDS re-educating sample buffered solution and boiling for $3 \mathrm{~min}$. The culture medium was incubated in $20 \mathrm{mM}$ phosphate buffer plus $5 \mathrm{~m}$ units endoglycosidase $\mathrm{H}$ (EC 3.2.1.96) (pH $5.5)$ at $25^{\circ} \mathrm{C}$ for $12 \mathrm{hr}$. Protease activity was inhibited by $0.5 \mathrm{mM}$ PMSF.

\section{Results}

\section{Ovarian development}

Eyestalk ablation was used to induce ovarian development; $80 \%$ of the eyestalk-ablated ani- mals spawned within 7 days (Table 1). The green color of the ovaries may be derived from carotenoids associated with vitellogenins. Animals in stage $I$ were used. Using hemotoxylin-eosin (HE) stain (Fig. 1A), the ovaries appeared to be in vitellin stage (diameter $40-200 \mu \mathrm{m}$ ). Using PAS stain (Fig. 1B), the vitellinic oocytes (diameter $>100 \mu \mathrm{m}$ ) showed an accumulation of large numbers of glycoproteins.

\section{Immunofluorescence microscopy}

The early maturation oocytes (diameter $<100 \mu \mathrm{m}$ ) neither react to the antiserum nor exhibit fluorescence (Figs 2A,B). The late-stage vitellogenic oocytes had significant fluorescence that was not observed in the early-stage oocyte. The follicular cell around the late-stage oocyte reacted with the anti-Ep antiserum showing strong fluorescence. The reabsorbed oocytes 


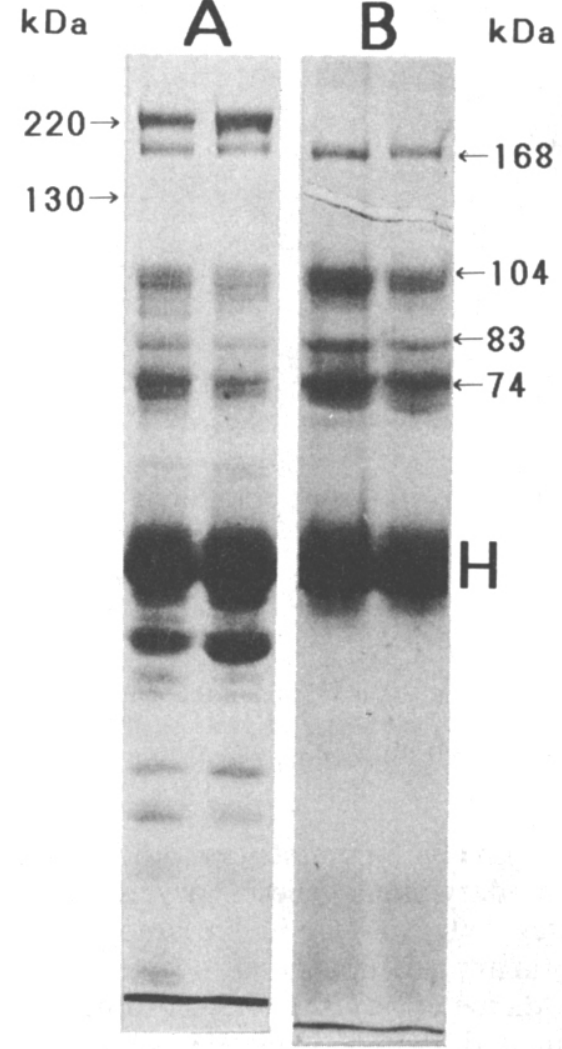

Fig. 3. SDS-PAGE (10\% acrylamide) of immunoprecipitates from in vitro culture ovary samples. A, ovary extract: B, culture medium.

(Fig. 2D) exhibited vitellin transport to the new maturation oocytes.

\section{Immunoprecipitates of vitellin in ovaries}

Vitellin-like proteins of tissues in vitro were electrophoretically analysed. Immunoprecipitates by anti-Vn antiserum and protein from the tissues and medium were tested using SDS-PAGE. Figure 3 shows that the ovary extract possesses five major bands of 200,168 , 104,83 and $74 \mathrm{kDa}$ molecular weight, respectively, and one minor band of $130 \mathrm{kDa}$. The cultured medium revealed similar patterns but lacked the $220 \mathrm{kDa}$ band.

The in vitro culture medium had three new polypeptides, with mol. wt of 70,78 and $95 \mathrm{kDa}$, respectively. In the proteolytic map, the $78 \mathrm{kDa}$ polypeptide was observed as $\mathrm{Vp} 3(83 \mathrm{kDa})$, and the $95 \mathrm{kDa}$ peptide as $\mathrm{Vp} 2$ (104 kDa) (Fig. 4).

Vitellogenin was treated with Endo-H to determine carbohydrates. The $220 \mathrm{kDa}$ peptide to Endo-H showed a reaction of about $20 \mathrm{kDa}$ (Fig. 5A). The other vitellin protein showed no difference when Endo-H-treated. These results may suggest that the $220 \mathrm{kDa}$ peptide was a mass glycolation, and that other peptides contained little or no carbohydrate. In the Sudan Black B stain, the $\mathrm{Vp} 1$ and $220 \mathrm{kDa}$ vitellin proteins stained positively, as shown in Fig. 5B. After digestion with alkaline phosphatases, $\mathrm{Vg}$ revealed no degradation (Fig. 5C).

\section{In vitro protein synthesis}

The result obtained from ${ }^{35} \mathrm{~S}$-methionine labeling (Figs 6A,B) showed new synthesis of ovarian polypeptides in vitro. After $1 \mathrm{hr}$ of culture, three new synthesized patterns were present in the ovary extract, with mol. wt of 220 , 168 and $130 \mathrm{kDa}$, respectively. Eight hours after culture, the three patterns were more intense, and some smaller patterns were present. In the culture medium, $1 \mathrm{hr}$ after culture, two patterns were found with mol. wt 168 and $74 \mathrm{kDa}$, respectively. There were no other patterns found in culture medium with incubation periods of up to $8 \mathrm{hr}$. Autoradiography showed that the ovary may synthesize vitellin-like proteins, with mol. wt of $220,168,130$ and $74 \mathrm{kDa}$, plus several smaller polypeptides. In the ovary, there were three patterns of 220,168 and $130 \mathrm{kDa}$, respectively. The culture medium contained two secreted polypeptides of 168 and $74 \mathrm{kDa}$ (Fig. 6D), respectively.

Immunoreactions of $\mathrm{P}$. monodon vitellin with $\mathrm{P}$. japonicus vitellin

Results of immunoblotting demonstrate the cross-reaction of $P$. monodon vitellin antiserum with ovarian extracts and hemolymph from mature female $P$. japonicus shrimp (Fig. 7). Anti-Epl reacted with one $70 \mathrm{kDa}$ vitellin protein only. The anti-Ep2 reacted with the $80 \mathrm{kDa}$ protein, and also showed weak cross-reaction to the $100 \mathrm{kDa}$ protein and the large vitellin

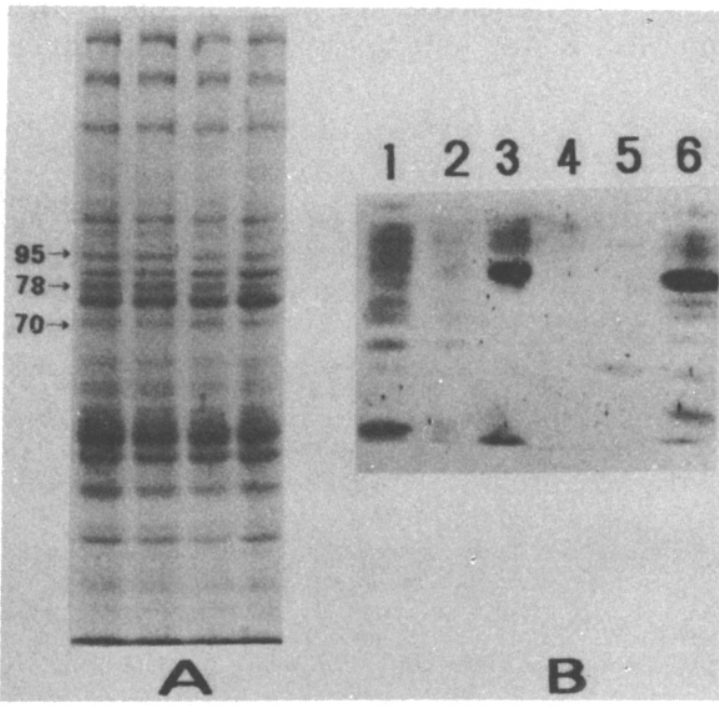

Fig. 4. Immunoblot of peptide maps of in vitro culture medium after partial proteolysis. A, $10 \%$ SDS-PAGE of culture medium; B, partial proteolysis of the vitellin-like polypeptides. $1,104 \mathrm{kDa} ; 2,95 \mathrm{kDa} ; 3,83 \mathrm{kDa} ; 4,78 \mathrm{kDa}$; $5,74 \mathrm{kDa} ; 6$, culture medium. 


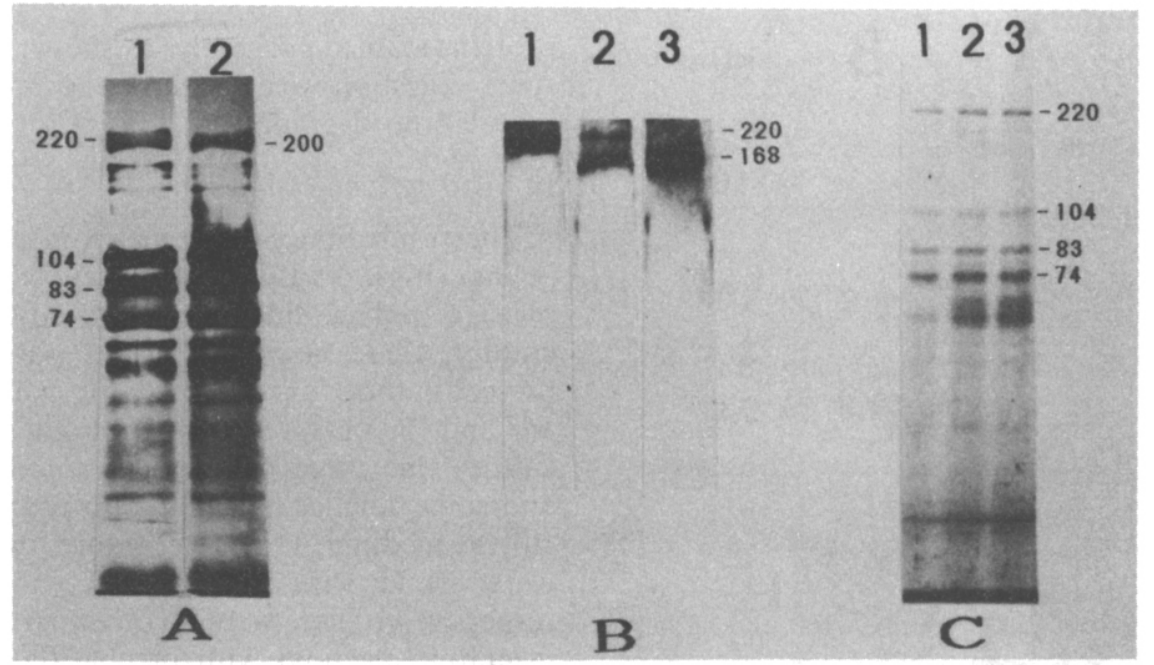

Fig. 5. Effect of Endo-H and calf alkaline phosphatase (CAP) on the $P$. monodon ovary vitellin subunits. A, Endoglycosidase- $\mathrm{H}$ treatment: 1, ovary extract; 2, Endo- $\mathrm{H}$ digestion, $12 \mathrm{hr}$. B, Sudan Black B stain: 1, early maturation stage ovary extract; 2 , late maturation stage ovary extract; 3 , egg extract. C, CAP treatment: 1 , ovary extract; 2 , CAP digestion, $1 \mathrm{hr} ; 3$, CAP digestion, $2 \mathrm{hr}$.

protein $(160 \mathrm{kDa})$. The anti-Ep3 reacted to the $100 \mathrm{kDa}$ and some larger proteins with mol. wt ranging from 130 to $170 \mathrm{kDa}$.

\section{Discussion}

The eyestalk-ablated broodstock females entered the vitellogenin stage, which was followed by spawning. The secondary vitellogenin period is less than 4 days; the yolk protein of the spawning eggs is synthesized in this period. Therefore, the vitellin production tissues were found to be at the peptide translation stage.

Vitellogenesis includes the production of vitellogenin and the accumulation of both organic and inorganic constituents of yolk by the oocytes. In the anti-Ep antisera immunostain
(Fig. 2A), vitellin commences to accumulate in the secondary vitellogenesis oocytes (yolk globular stage). However, vitellin is not present in the primary vitellogenesis oocytes (pre-yolk stage, diameter $<100 \mu \mathrm{l})$. According to TanFermin and Pudadera (1991), all the mature oocytes may be spawned out. The atretic oocytes in the secondary vitellogenesis period degenerate and are reabsorbed (Harrison, 1990). In Fig. 2B, the vitellin of degenerating oocytes is transferred to the newly matured oocytes. Vitellin appeared to be used not only for yolk protein formation, but also for nutritious transfer in the vitellogenesis stage.

In the immunoprecipitates of ovary extract and culture, five major vitellin-like peptides occurred. The $220 \mathrm{kDa}$ peptide is only present in

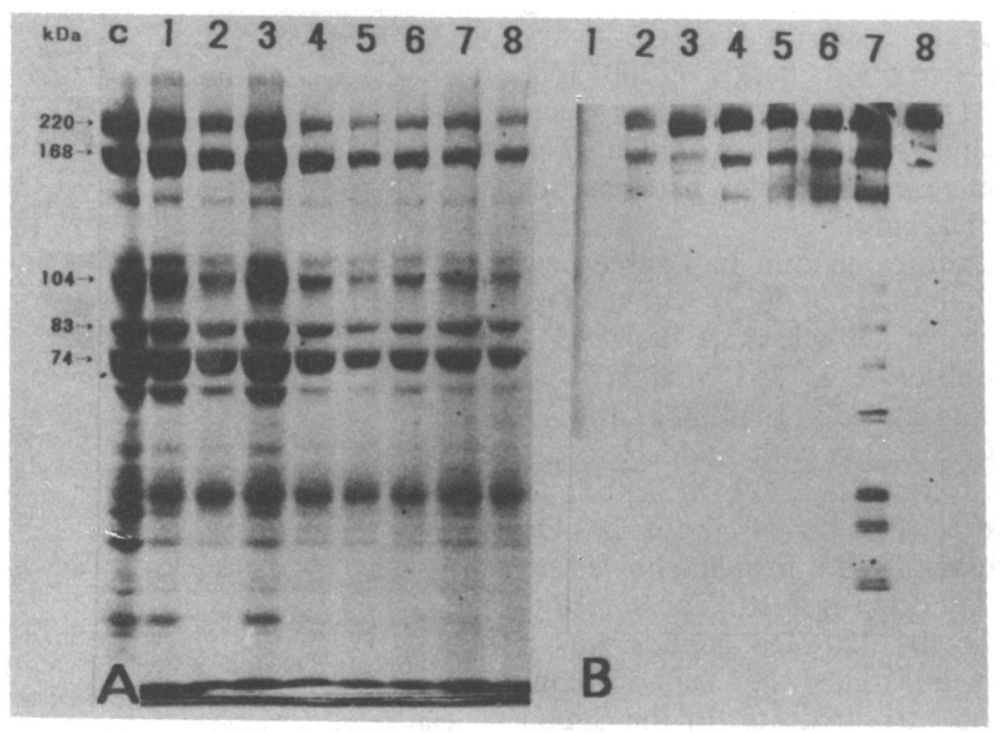

Fig. 6A and $B$ 


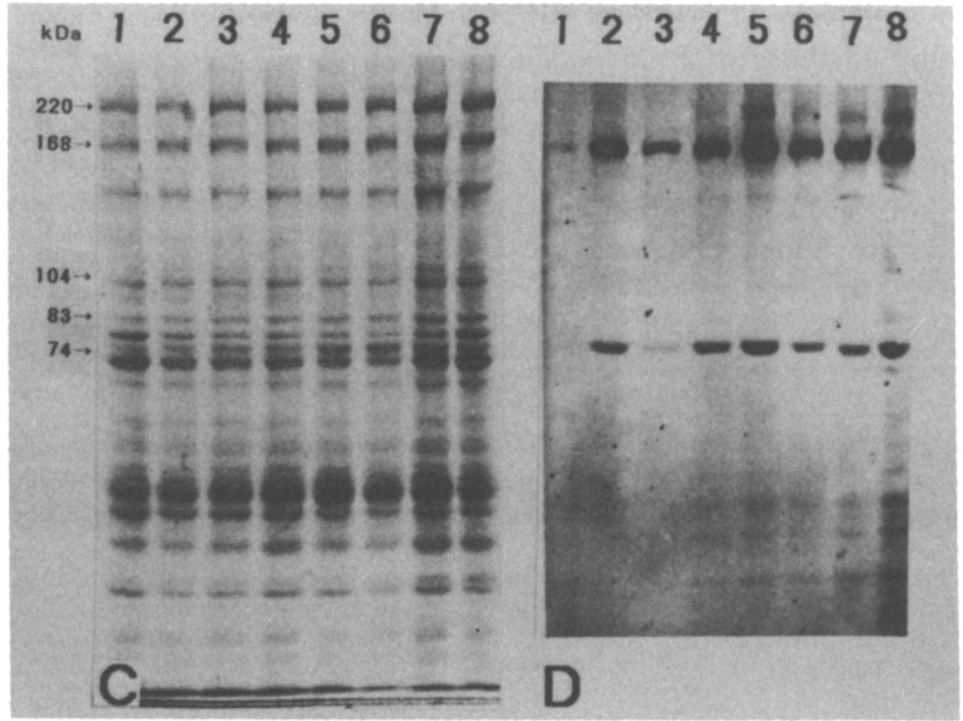

Fig. 6. [ ${ }^{35}$ S]methionine labeling of in vitro culture ovary proteins. SDS-PAGE fluorography of immunoprecipitates for culture ovary samples. A, C, Coomassie Blue R stain; B, D, autoradiography. A, B, ovary extract; C, D, culture medium. The culture times, C, $0 \mathrm{hr} ; 1,0.5 \mathrm{hr} ; 2,1 \mathrm{hr} ; 3,2 \mathrm{hr} ; 4,3 \mathrm{hr} ; 5,4 \mathrm{hr} ; 6,5 \mathrm{hr}$; $7,6 \mathrm{hr} ; 8,8 \mathrm{hr}$.

the early secondary vitellogenesis ovary. The result of Sudan Black B and PAS staining may suggest that the $220 \mathrm{kDa}$ variant is a glycolipoprotein. In in vitro culture of the ovary, three newly synthesized vitellin peptides were present in ovary extract with mol. wt 220, 168 and $130 \mathrm{kDa}$; and two secretory peptides in the culture medium of mol. wt 168 and $74 \mathrm{kDa}$. The isolated vitellogenin in hemolymph of $P$. monodon is composed of two subunits with mol. wt 170 and $93 \mathrm{kDa}$ (Lee, 1991); that is, it is very similar to the secretory vitellin found in in vitro culture. In our present study, $P$. monodon hemolymph contained four egg yolk peptides of 168 , 104,83 and $74 \mathrm{kDa}$. These may be derived from the reabsorption of vitellin in hemolymph and newly synthesized vitellogenin. In $P$. japaneus, the ovary synthesized two vitellin proteins (Yano and Chinzei, 1987). In P. semisulcatus, vitellin protein can be synthesized by the ovary in vitro as native vitellin that consists of four subunits (Browdy et al., 1990). Lui and O'Connor (1977) concluded that the ovaries of crab, Pachygrapsus crassipes, are capable of synthesizing the proteinaceous yolk found in the mature egg.

Our results did not show Ep2 and Ep3 to be synthesized in ovaries in vitro. It may be that the culture time was too short for vitellin to be processed, or that it cannot be processed in in vitro culture. From our data, it may be concluded that $P$. monodon ovary synthesizes vitellin in vitro. A $220 \mathrm{kDa}$ pre-vitellin and two intermediate vitellins (168 and $130 \mathrm{kDa})$ were found in the ovary, and 168 and $74 \mathrm{kDa}$ vitellins were secretory to culture medium. In vivo, the 168 and $74 \mathrm{kDa}$ peptides may constitute vitellogenin and show absorption by oocytes.

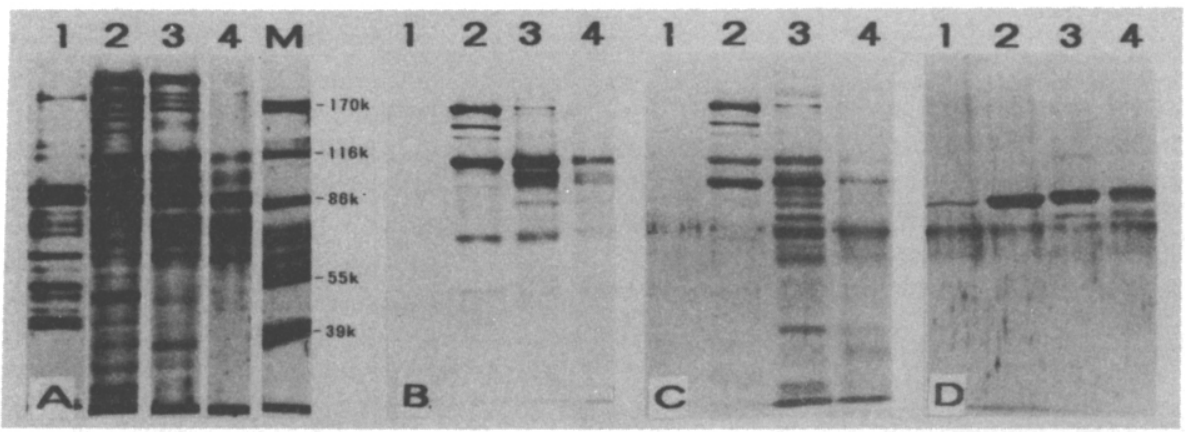

Fig. 7. Immunoblotting showing the cross-reactivity of antiserum to vitellin of $P$. monodon $(\mathrm{Pm})$ with $P$. japonicus (Pj). A, silver stain; B, C, D, immunostain. B, anti-Ep2. B, anti-Ep3. C, anti-Ep2. 1, hemolymph of $\mathrm{Pj} ; 2$, ovary extract of $\mathrm{Pj} ; 3$, ovary extract of $\mathrm{Pm} ; 4$, egg extract. 
The vitellin of $P$. japonicus has four subunits that are similar to those of $P$. monodon. When immunostained, they reacted to the anti$\mathrm{Vg}$ antisera of $P$. monodon. This result may suggest that vitellins in $P$. monodon and $P$. japonicus penaeids are very similar immunologically and may mature under the same processes.

\section{References}

Aiken D. E. and Waddy S. L. (1980) Reproductive biology. In The Biology and Management of Lobster Edited by Cobb J. S. and Phillips B. F.), Vol. I. Physiology and Behaviour. pp. 215-276. Academic Press, New York.

Browdy C. L., Fainzlber M., Loya T. Y. and Lubzens E. (1990) Vitellin synthesis in relation to oogenesis in in vitro-incubated ovaries of Penaeus semisulcatus (Crustacea, Decapoda, Peneidae). J. Exp. Zool. 255, 205-215.

Chen C. C. and Chen S. N. (1993) Isolation and partial characterization of vitellin from the egg of giant tiger prawn, Penaeus monodon. Comp. Biochem. Physiol. 106B, 141-146.

Chen S. N., Jong K. J. and Kou G. H. (1989) Cell cultures derived from tissue of penaeid shrimp, Penaeus penicillatus and hard clam, Meretrix lusoria. In Invertebrate Cel System Applications (Edited by Mitsuhashi J.), Vol. 2, pp. 253-262. CRC Press, Boca Raton, FL.

Harrison K. E. (1990) The role of nutrition in maturation, reproduction and embryonic development of decapod crustaceans: a review. J. Shellfish Res. 9, 1-28.

Laemmli U. K. (1970) Cleavage of structural protein during the assembly of the bacteriophage T4. Nature 227, 680-685.

Lee F. Y. (1991) Purification and quantification of vitellogenin and vitellin in the tiger prawn, Penaeus monodon.
Masters Thesis, National Taiwan Ocean University, Taiwan.

Lui C. W. and O'Connor J. D. (1977) Biosynthesis of crustacean lipovitellin. III. The incorporation of labeled amino acids into the purified lipovitellin of the crab Pachygrapsus crassipes. J. Exp. Zool. 199, 105-108.

Motoh H. (1981) Studies on the fisheries biology of the giant tiger prawn, Penaeus monodon, in the Philippines, pp. 16-19. Aquaculture Department, Southeast Asian Fisheries Development Center, Philippines.

Paulus, J. E. and Laufer H. (1987) Vitellogenocytes in the hepatopancreas of Carcinus maenas and Libinia emarginata (Decapoda, Brachyura) Int. J. Invert. Reprod. Dev. 11, 29-44.

Quackenbush L. S. (1989) Vitellogenesis in the shrimp, Penaeus vannamei: in vitro studies of the isolated hepatopancreas and ovary. Comp. Biochem. Physiol. 94B, 253-261.

Quinitio E. T., Hara A., Yamauchi K. and Fuji A. (1990) Isolation and characterization of vitellin from the ovary of Penaeus monodon. Int. J. Invertebr. Reprod. Devel. 17, 221-227.

Rankin S. M., Bradfield J. Y. and Keeley L. L. (1989) Ovarian protein synthesis in the South American shrimp. Penaeus vannamei, during the reproductive cycle. Int. J. Invertebr. Reprod. Devel. 15, 27-33.

Tan-Fermin J. D. and Pudadera R. A. (1989) Ovarian maturation stages of the wild giant tiger prawn Penaeus monodon Fabricius. Aquaculture 77, 229-242.

Tom M., Goren M. and Ovadia M. (1987) Purification and partial characterization of vitellin from the ovaries of Parapenaeus longirostris (Crustacea, Decapoda, Penaeidae). Comp. Biochem. Physiol. 87B, 17-23.

Vazquez-Boucard C. and Ceccaldi H. J. (1986) Identification, purification, et caractérisation de la lipovitellin chez un crustace décapode natantia Penaeus japonicus (Bate). J. Exp. Mar. Biol. Ecol. 97, 37-50.

Yano I. and Chinzei Y. (1987) Ovary is the site of vitellogenin synthesis in kuruma prawn, Penaeus japonicus. Comp. Biochem. Physiol. 86B, 213-218. 